\title{
ANALISIS PERBANDINGAN ANTARA PUPUK ORGANIK URIN KELINCI DENGAN PUPUK NON-ORGANIK (NPK MUTIARA) TERHADAP PENDAPATAN DAN HASIL PANEN WORTEL DI DESA HANAKAU KABUPATEN LAMPUNG BARAT
}

\author{
Susanti Sundari, Rahmad Abdulloh \\ Program Studi Teknik Industri Fakultas Teknik \\ Universitas Tulang Bawang Lampung
}

\begin{abstract}
Hanakau Village, Sukau District, West Lampung Regency is a village where most people depend on agriculture for their livelihoods. The main commodities grown in Hanakau Village are carrots, cabbage, sweet potatoes, and other types of vegetables such as mustard greens, tomatoes, peanuts, beans and chillies. Farmers there need chemical fertilizers, manure or animal dung in large quantities to fertilize the growth of vegetable crops. The use of chemical fertilizers in the village of Hanakau on agricultural land has continuously had a negative impact on the soil and the environment.

Animals that are kept and used for manure in Hanakau Village are goats and rabbits. Rabbit urine has the highest nitrogen content compared to manure and urine of other livestock such as horses, buffaloes, cows, and sheep, because it is customary to never drink water and only consume green leaves and carrots.

This study aims to see how far the difference between carrots and what are the economic benefits of using organic fertilizer (rabbit urine) and inorganic fertilizer (NPK Mutiara). The parameters observed in this study were plant height, number of leaf segments, measuring the diameter of the base of carrot tubers ready for harvest at 3 months. And the analysis used is to see an overview of the components of costs incurred and the benefits to be gained.

The conclusion obtained is the growth of carrot plants using rabbit urine organic fertilizer and non-organic NPK Mutiara is not too significant difference. But there is a significant difference in net income for rabbit urine. The use of rabbit urine organic fertilizer is more profitable in terms of lower production costs (IDR 70,000) and higher income (IDR 130,000) compared to inorganic fertilizers (NPK Mutiara)
\end{abstract}

Keywords: Organic fertilizer, inorganic fertilizer, rabbit urine, NPK Mutiara, carrot

\section{Pendahuluan}

Desa Hanakau, Kecamatan Sukau, Kabupaten Lampung Barat merupakan Desa yang sebagian besar masyarakatnya menggantungkan kehidupan disektor pertanian, perkebunan, buruh angkut sayuran dari lahan pertanian. Adapun luas kelurahan Hanakau $6,859 \mathrm{Km}^{2}$ terdiri dari 7 Kampung. Sebagian besar komoditas utama yang ditanam di Desa Hanakau ialah wortel, kubis, umbi jalar, dan jenis sayuran lain seperti, sawi, tomat, kacang tanah, buncis dan cabe. Petani disana memerlukan pupuk kimia, pupuk kandang atau kotoran hewan ayam dalam jumlah besar untuk pemupukan pada pertumbuhan tanaman sayuran. Penggunaan pupuk kimia di Desa Hanakau dilahan pertanian yang terus menerus telah mengakibatkan dampak negatif bagi tanah dan lingkungan. Dampak negatif yang ditimbulkan adalah rusaknya struktur tanah dan lingkungan tanah menjadi tidak bagus lagi untuk 
ditanami dan tidak menghasilkan hasil tanaman yang konsisten, dikarenakan unsur hara yang terdapat pada tanah semakin berkurang. Nutrisi pada pupuk nonorganik, terutama nitrat, dapat mencemari lingkungan alam dan mengganggu kehidupan manusia jika terbilas oleh air hujan dan mengalir dari lahan pertanian hingga ke perairan setempat dan air tanah. Jumlah pupuk non-organik yang masuk ke perairan cenderung sulit untuk dihitung dan diperkirakan dampaknya secara kuantitatif.Memupuk berarti menambah unsur hara kedalam tanah dan tanaman.

Secara umum pupuk dibagi dalam dua kelompok berdasarkan asalnya, yaitu pupuk Non-organik seperti urea (senyawa yang tersusun dari unsur karbon, oksigen, nitrogen), SP-36 (super fosfat), NPK Mutiara, $\mathrm{KCl}$ (kalium clorida), TSP (nutrient non-organik yang digunakan untuk meningkatkan unsur hara pertanian), dan pupuk Organik seperti pupuk kadang, humus, kompos, dan pupuk hijau, (Heru Prihmantoro, Y.H. Indriani, 2017). Pupuk non-organik tidak mempunyai sifat yang dapat memperbaiki sifat dan fungsi fisik dan biologi tanah secara langsung. Meningkatnya kesadaran bahwa dengan pemberian pupuk organik sifat dan fungsi fisik tanah menjadi bagus dan tanaman menjadi tumbuh dengan baik telah menyebabkan meningkatnya tren tanaman organik, sehingga mengakibatkan penggunaan pupuk organik meningkat. Pupuk organik terdiri dari limbah/hasil pertanian berupa sisa tanaman hasil pertanian, pupuk kandang dan lain-lain. Penambahan bahan organik khususnya pada tanah sawah sangat diperlukan karena 95\% lahan pertanian di Indonesia mengandung bahan organik kurang dari $1 \%$, padahal minimal kandungan kandungan bahan organik yang dianggap layak untuk lahan pertanian adalah 4-5\% (Khairunisa. 2015 ).

Untuk menyokong pertumbuhan sayuran yang ditanam oleh masyarakat Desa Hanakau digunakan pupuk organik. Karena, selain membuat tanaman tumbuh dengan subur dan juga pupuk organik sedikit demi sedikit akan mengngembalikan unsur hara tanah yang mulai rusak sehingga diperoleh hasil tanaman yang setabil. Selain itu, pupuk organik yang berasal dari kotoran hewan seperti pupuk kandang, mengandung unsur hara makro dan mikro. Pupuk kandang padat banyak mengandung unsur hara makro, seperti fosfor, nitrogen, dan kalium. Unsur hara mikro yang terkandung dalam pupuk kandang padat di antaranya kalsium, magnesium, belerang, natrium, besi, tembaga, dan timbal. Adapun pupuk kandang cair dapat diproleh dari urin hewan ternak, karena kandungan nitrogen dalam urin hewan ternak tiga kali lebih besar dibandingkan dengan kandungan nitrogen dalam kotoran padat, menurut Musnawar dalam (Enny Mutryaarny, Endriani, dkk. 2014). Unsur nitrogen merupakan salah satu unsur hara paling penting yang ada di permukaan bumi. Sebagian besar masyarakat Hanakau dimana setiap kepala rumah tangga memelihara hewan ternak seperti kelinci, kambing, sapi, dan ayam sebagai hewan peliharaan. Kotoran dari hewan ternak dimanfaatkan untuk memupuk tanaman atau sayuran yang akan ditanam. Hewan yang dipelihara dan digunakan kotorannya di Desa Hanakau adalah kambing dan kelinci. Kotoran kambing diberikan dengan cara di taburkan atau disebar ke lahan yang akan di tanami sayuran, sedangkan kotoran urin kelinci di tampung pada wadah ember atau botol dan digunakan untuk penyeprotan pada tanaman sayuran. Pemberian pupuk urin kelinci ada kalanya di campur dengan peptisida sebagai pembasmi hama.

Pemberian pupuk organik pada tanaman setiap kali menanam akan mempercepat pertumbuhan tanaman yang ditanam, seperti halnya sayuran wortel yang merupakan salah satu sumber vitamin dan mineral essensial yang sangat dibutuhkan oleh tubuh manusia, selain itu sayuran wortel yang berwarna orange ini banyak mengandung nutrisi penting (Tabel 1), vitamin A, mineral dan anti-oksidan lain 
dalam jumlah yang cukup tinggi. Wortel dengan rasanya yang manis, lezat dan renyah, sangat baik bagi tubuh (Ir. Rahmat Rukmana, 1997). Bagian yang dapat dimakan dari wortel adalah bagian umbi dan akarnya. Cadangan makanan ini di simpan didalam umbi. Kandungan nutrisi yang terdapat dalam 100 gr bahan sayuran wortel dapat di lihat pada tabel 1. Berikut ini:

Tabel 1. Kandungan gizi dalam tiap 100 gr umbi wortel segar

\begin{tabular}{|l|c|c|}
\hline \multicolumn{2}{|c|}{ Kandungan gizi } & \multicolumn{2}{c|}{ Banyaknya } \\
\cline { 2 - 3 } & Wortel muda & Wortel tua \\
\hline Kalori & $42,00 \mathrm{kal}$ & $55,00 \mathrm{kal}$ \\
\hline Protein & $1,20 \mathrm{gr}$ & $1,30 \mathrm{gr}$ \\
\hline Lemak & $0,30 \mathrm{gr}$ & $0,40 \mathrm{gr}$ \\
\hline Karbohidrat & $0,30 \mathrm{gr}$ & $12,40 \mathrm{gr}$ \\
\hline Kalsium & $39,00 \mathrm{mg}$ & $60,00 \mathrm{mg}$ \\
\hline Fosfor & $37,00 \mathrm{mg}$ & $28,00 \mathrm{mg}$ \\
\hline Zar besi & $0,80 \mathrm{mg}$ & $1,70 \mathrm{mg}$ \\
\hline Vitamin A & $12000,00 \mathrm{~S} . \mathrm{I}$ & $18000,00 \mathrm{~S} . \mathrm{I}$ \\
\hline Vitamin B1 & $0,06 \mathrm{mg}$ & $0,04 \mathrm{mg}$ \\
\hline Vitamin C & $6,00 \mathrm{mg}$ & $9,00 \mathrm{mg}$ \\
\hline Serat & - & $0,90 \mathrm{gr}$ \\
\hline Abu & - & $0,80 \mathrm{gr}$ \\
\hline Natrium & - & $32,00 \mathrm{mg}$ \\
\hline Vitamin B2 & - & $0,04 \mathrm{mg}$ \\
\hline Niacin & - & $0,60 \mathrm{mg}$ \\
\hline Air & $88,20 \mathrm{gr}$ & - \\
\hline
\end{tabular}

Sumber: Sitijati D. Sastrapradja, (2012).

Keterangan: wortel muda dipanen umur 3 bulan, wortel matang atau wortel berumur tua dipanen umur $>3$ bulan $<4$ bulan.

Tanaman ini memerlukan pemupukan yang intensif dengan jumlah banyak, terutama unsur nitrogen, fosfor dan kalsium serta unsur mikro. Untuk pertumbuhan dan produksi yang berkualitas seperti yang diharapkan maka dilakukan penelitian dengan pemberian pupuk organik cair urin kelinci.

Penelitian ini bertujuan untuk melihat seberapa jauh perbedaan hasil tanaman wortel apa saja keuntungan ekonomis dengan menggunakan pupuk organik (urin kelinci) dan pupuk nonorganik (npk mutiara).

\section{Tinjauan Pustaka \\ Pengertian Pupuk}

Pupuk adalah material yang ditambahkan pada media tanam atau tanaman untuk mencukupi kebutuhan hara yang diperlukan tanaman sehingga mampu berproduksi dengan baik material pupuk dapat berupa bahan organik ataupun nonorganik (mineral). Pupuk berbeda dengan suplemen, pupuk mengandung bahan baku yang diperlukan pertumbuhan dan perkembangan tanaman, sementara suplemen seperti hormon pertumbuhan membantu kelancaran proses metabolisme. Meskipun demikian, ke dalam pupuk, khususnya pupuk buatan, dapat ditambahkan sejumlah material suplemen (Panji Nugroho, 2017). Pupuk kimia biasanya lebih "murni" daripada pupuk organik, dengan kandungan bahan yang dapat dikalkulasi. Pupuk organik sukar ditentukan isinya, tergantung dari sumbernya, keunggulannya adalah ia dapat memperbaiki kondisi fisik tanah karena membantu pengikatan air secara efektif.

\section{Pupuk Berdasarkan Bentuk Fisik Dan Kandungannya}

Berdasarkan bentuk fisiknya, pupuk dibedakan menjadi pupuk padat dan pupuk cair. Pupuk padat diperdagangkan dalam bentuk onggokan, remahan, butiran, atau kristal. Pupuk cair diperdagangkan dalam bentuk konsentrat atau cairan. Pupuk padatan biasanya diaplikan ke tanah/media 
tanam, sementara pupuk cair diberikan secara disemprot ke tanaman.

Terdapat dua kelompok pupuk berdasarkan kandungan: pupuk tunggal dan pupuk majemuk. Pupuk tunggal mengandung hanya satu unsur, sedangkan pupuk majemuk paling tidak mengandung dua unsur yang diperlukan. Terdapat pula pengelompokan yang disebut pupuk mikro, karena mengandung hara mikro (micronutrients). Beberapa merk pupuk majemuk modern sekarang juga diberi campuran zat pengatur tumbuh atau zat lainnya untuk meningkatkan efektifitas penyerapan hara yang diberikan.

\section{Manfaat Pupuk Organik}

Pupuk organik diketahui mampu meningkatkan keanekaragaman hayati pertanian dan produktivitas tanah secara jangka panjang. Pupuk organik juga dapat menjadi sarana sekuestrasi karbon ketanah (penangkapan dan penyimpanan karbon dioksida). Nutrisi organik meningkatkan keanekaragaman hayati tanah dengan menyediakan bahan organik dan nutrisi mikro bagi organisme penghuni tanah seperti jamur mikoriza yang membantu tanaman menyerap nutrisi, dan dapat mengurangi input pupuk (Panji Nugroho, 2017).

\section{Pupuk Organik Cair Urin Kelinci}

Kelinci memiliki kelebihan lain yang bisa dimanfaatkan untuk kegiatan pertanian yakni urin dan kotoran kelinci dijadikan pupuk organik. Air urin kelinci merupakan cairan yang mampu memberikan suplai nitrogen yang cukup tinggi bagi tanaman. Jika dibandingkan dengan hewan pemakan rumput lainnya, air urin kelinci memiliki kadar nitrogen yang tinggi karena kebiasan tidak pernah minum air dan hanya mengomsumsi dedaunan hijau dan wortel saja.

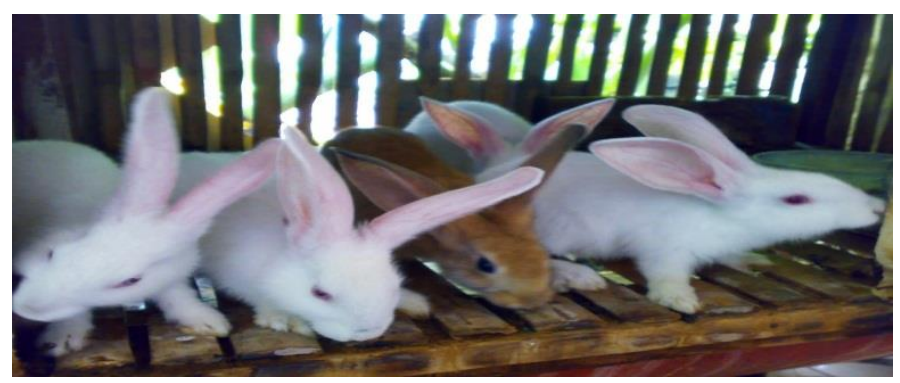

Gambar 1. Hewan kelinci

Urin kelinci yang disiramkan disekitar tanaman jagung saat berumur 7 hari setelah tebar hingga berbunga dengan pemberian 10 kali dapat meningkatkan hasil tanaman menurut Sitijati D. Sastrapradja dalam (Enny Mutryaarny, Endriani, dkk. 2014). Adapun kotoran dan urin kelinci memiliki kandungan unsur Nitrogen paling tinggi dibandingkan dengan kotoran dan urin ternak lainnya seperti kuda, kerbau, sapi, dan domba, (Panji Nugroho, 2017)

Tabel 2. Kandungan unsur urin hewan

\begin{tabular}{|l|l|l|l|l|}
\hline No & \multicolumn{4}{|c|}{ Kandungan unsur } \\
\hline & Hewan & $\begin{array}{c}\text { Nitrogen } \\
(\%)\end{array}$ & $\begin{array}{c}\text { Fosfor } \\
(\%)\end{array}$ & $\begin{array}{c}\text { Kalium } \\
(\%)\end{array}$ \\
\hline 1 & Kelinci & 2,75 & 1,1 & 0,5 \\
\hline 2 & Domba & 1,35 & 0,05 & 2,10 \\
\hline 3 & Kuda & 1,40 & 0,02 & 1,60 \\
\hline 4 & Kerbau & 1,00 & 0,15 & 1,50 \\
\hline 5 & Sapi & 1,00 & 0,50 & 1,50 \\
\hline
\end{tabular}

Sumber: (Panji Nugroho, 2017). 


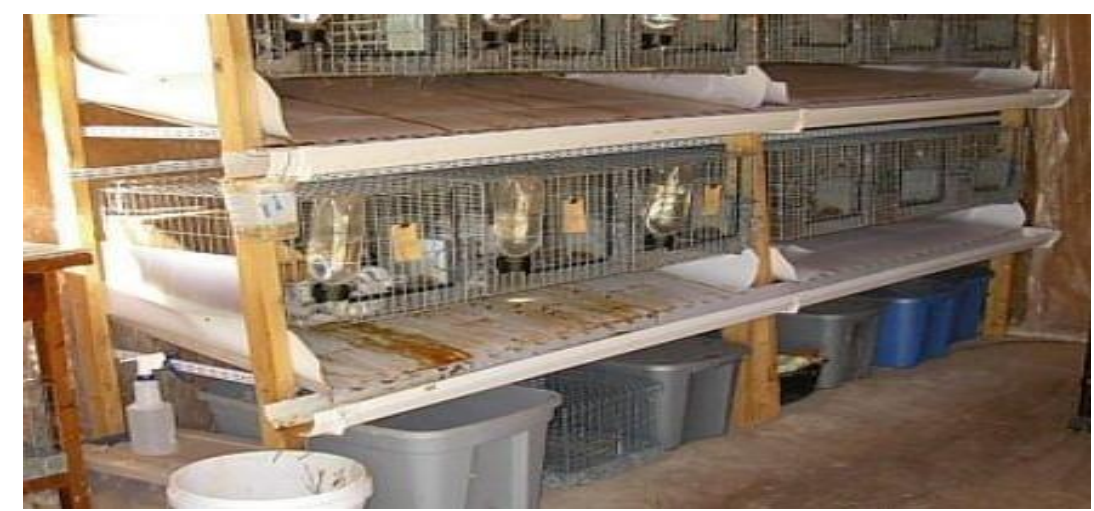

Gambar 2. Mengumpulkan urin kelinci.

Sumber: Data primer.

\section{Pupuk Non-organik (NPK Mutiara)}

Pupuk NPK Mutiara adalah salah satu jenis pupuk majemuk yang mengandung sedikitnya 5 unsur hara makro dan mikro yang sangat dibutuhkan tanaman. Pupuk ini berbentuk butiran granul berwarna biru pudar yang biasanya dikemas dalam kemasan satu sak karung dengan berat 50 $\mathrm{kg}$, plastik dengan berat $2 \mathrm{~kg}, 5 \mathrm{~kg}, 10 \mathrm{~kg}$. Pupuk NPK Mutiara dibuat menggunakan proses Odda melalui pelarutan batuan fosfat menggunakan asam nitrat. Pupuk NPK Mutiara hingga saat ini masih diimpor dari Norwegia oleh karenanya harganya masih tergolong cukup mahal, yakni Rp. 400.000 - Rp 600.000 per-karung. Kendati sangat mahal, pupuk ini tetap laris dipasaran karena khasiatnya yang cukup baik bagi pertumbuhan tanaman dengan reaksi yang cukup cepat. Pupuk NPK Mutiara mengandung 16\% N (Nitrogen), 16\% P2O5 (Phospate), $16 \%$ K2O (Kalium), $0.5 \%$

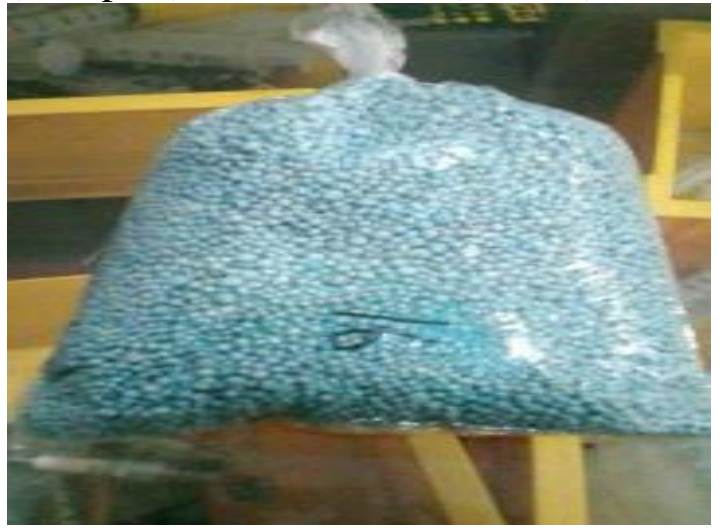

Gambar 3.Pupuk mutiara eceran Sumber: Data primer.
$\mathrm{MgO}$ (Magnesium), dan $\quad 6 \% \quad \mathrm{CaO}$ (Kalsium). Karena kandungan tersebut pupuk ini juga dikenal dengan istilah pupuk NPK 16-16-16. Pupuk ini memiliki banyak keunggulan dibanding pupuk NPK lainnya seperti pupuk NPK Phonska. Keunggulan tersebut diantaranya adalah:

1. Mengandung unsur hara NPK sekaligus hara mikro $\mathrm{CaO}$ dan $\mathrm{MgO}$ yang sangat dibutuhkan tanaman.

2. Dibuat menggunakan proses Odda sehingga bersifat mobile dan cepat bereaksi pada tanaman.

3. Menjaga keseimbangan unsur hara makro dan mikro pada tanah.

4. Aplikasinya yang cukup mudah sehingga biaya pemupukan relatif lebih kecil. 
Penggunaan pupuk ini tidak terbatas hanya untuk tanaman tertentu. Baik tanaman pangan, hortikultura, ataupun perkebunan, semuanya dapat menerima khasiat dan manfaat dari pupuk NPK mutiara ini. Pada tanaman keras seperti tanaman perkebunan, pupuk ini dapat diaplikasikan dengan menaburkannya sebanyak satu sendok teh pada tanah di sekitar perakaran tanaman. Sedangkan untuk tanaman hortikultura penggunaannya dapat dengan diencerkan

\section{Tanaman Wortel}

Wortel adalah tumbuhan biennial (siklus hidup 12 - 24 bulan) yang menyimpan karbohidrat dalam jumlah besar untuk tumbuhan tersebut berbunga pada tahun kedua. Batang bunga tumbuh setinggi

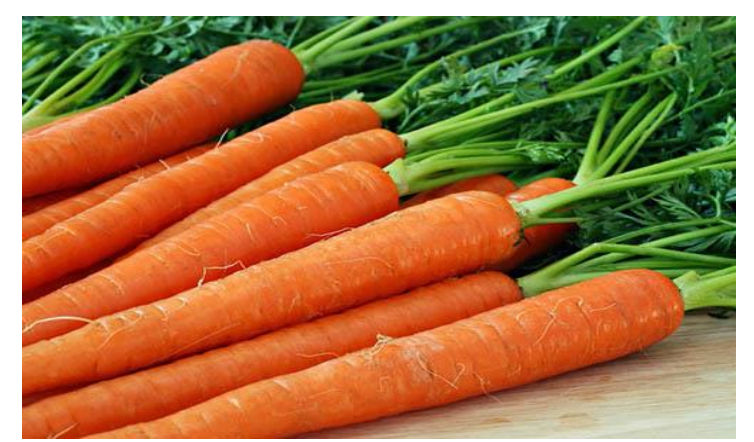

Gambar 4. Wortel segar

Sumber : htt//:wortel.waring123.com.

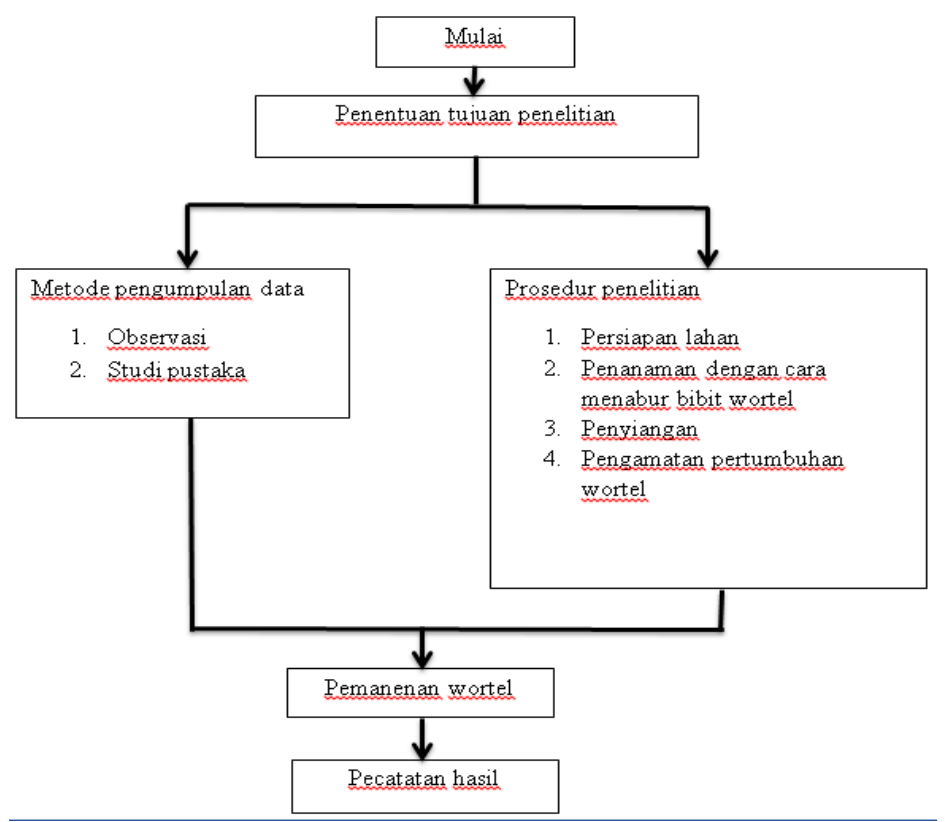

Gambar 5. Kerangka Pemikiran sekitar $1 \mathrm{~m}$, dengan bunga berwarna putih, dan rasa yang manis langu. Bagian yang dapat dimakan dari wortel adalah bagian umbi atau akarnya. Wortel dapat dimakan dengan berbagai cara. Adapun wortel biasanya dikomsumsi sebagai campuran sayur sop, sayur tumis, dan digunakan untuk membuat kue seperti pudding wortel, jus wortel dan lain-lain.

Wortel mengandung vitamin A yang baik untuk kesehatan mata. Mengkonsumsi wortel baik untuk penglihatan pada mata, terutama bisa meningkatkan pandangan jarak jauh. Selain vitamin $A$, wortel juga mengandung vitamin B1, B2, B3, B6, B9, dan C, kalsium, zat besi, magnesium, fosfor, kalium, dan sodium. 
Metodologi Penelitian

\section{Teknik Pengumpulan Data}

Metode pengumpulan data yang digunakan dalam penelitian ini adalah dengan observasi (pengamatan langsung) dan studi pustaka.

\section{Prosedur Penelitian}

\section{-Persiapan Lahan Penanaman}

Persiapan lahan yang akan dipakai untuk penanaman wortel dengan cara menyangkul lahan atau dibajak agar tanah yang akan ditanami wortel gembur kemudian dibuat seperti siring (selokan) menggunakan cangkul.

\section{-Pemberian pupuk}

Pemberian pupuk organik dan nonorganik ke lahan yang belum dibuat gulutan dengan cara disebar secara merata ke gulutan.

\section{-Penanaman}

Penanaman atau penaburan dilakukan menggunakan tangan ditabur kegulutan yang telah jadi. Bibit wortel di tabur ke gulutan dengan rata supaya tumbuhan wortel terlalu jarang. Wortel akan tumbuh secara merata pada umur 10 hari setelah tanam.

\section{-Penyiangan}

Penyiangan dilakukan untuk mengendalikan gulma di sekitar tanaman yang dilakukan sebanyak 1 kali. Penyiangan pertama dilakukan pada umur 40 hari setelah tanam dengan cara mencabut gulma.

\section{-Pengendalian Hama}

Pengendalian hama dan penyakit merupakan tidak perlindungan tanaman dari ancaman kerusakan yang ditimbulkan.

\section{Pemanennan Wortel}

Wortel dapat dipanen pada umur 34 bulan dari pertama menanam. Tandatanda wortel yang siap panen dengan daun yang sudah mulai turun kebawah dengan ditandai dengan munculnya pucuk daun yang membentuk batang yang akan menjadi bunga wortel.

\section{Variabel Pengamatan}

Parameter yang diamati dalam penelitian ini yaitu; a. Tinggi tanaman, diukur seminggu sekali dan yang diukur mulai pangkal batang sampai ujung daun tertinggi.

b. Jumlah ruas daun, pengamatan jumlah ruas daun dihitung pada daun yang telah membuka sempurna dan daun yang masih kucup tidak dihitung.

c. Mengukur diameter pangkal umbi wortel yang siap panen berumur 3 bulan.

\section{Analisis Data}

Analisa yang digunakan untuk melihat gambaran mengenai komponen biaya yang dikeluarkan dan keuntungan yang akan diperoleh. Selanjutnya, Soekartawi (1995) mengatakan, bahwa pada analisis usaha tani terdapat perhitungan ratio yang digunakan untuk mengetahui perbandingan antara penerimaan dan biaya yang telah dikeluarkan.

\section{Penerimaan}

Total penerimaan (Total Return) adalah perkalian antara produksi yang diperoleh dengan harga jual, secara matematis dirumuskan sebagai berikut :

$$
\mathbf{T R}=\mathbf{P} \times \mathbf{Q}
$$

Keterangan :

TR = Total Return / Total Penerimaan (Rp)

$$
\begin{array}{ll}
\mathrm{P} & =\text { Price } / \text { Harga }(\mathrm{Rp} / \mathrm{Kg}) \\
\mathrm{Q} & =\text { Quantity } / \text { Produksi }(\mathrm{Kg})
\end{array}
$$

\section{Pendapatan}

Untuk mengetahui berapa besar pendapatan bersih yang diperoleh dari hasil penanaman wortel yang menggunakan pupuk organik urin kelinci dan pupuk nonorganik npk (mutiara), dari usaha tani yang dijalankan, secara matematis dapat dirumuskan sebagai berikut :

$$
\mathbf{I}=\mathbf{T R}-\mathbf{T C}
$$

Keterangan:

$$
\begin{aligned}
& \mathrm{I} \quad=\text { Pendapatan bersih (Income) } \\
& \mathrm{TR} \quad=\text { Total return atau total } \\
& \text { penerimaan }(\mathrm{Rp}) \\
& \mathrm{TC} \quad=\text { Total cost atau total biaya ( } \mathrm{Rp})
\end{aligned}
$$

\section{Hasil dan Pembahasan}


Persiapan Lahan, Pembuatan Gulutan dan Pemberian Pupuk

Penggemburan tanah dengan kedalaman 20 sampai $30 \mathrm{~cm}$.

Pembuatan gulutan untuk tanaman wortel dengan lebar $1 \mathrm{~m}$ x $20 \mathrm{~m}$ dengan dengan kedalaman $30 \mathrm{~cm}$. Langkah pertama yang dilakukan adalah mebendeng lahan dengan menggunakan tali, kemudian lahan yang telah dibendeng dinaikan atau digaris dengan menggunakan cangkul. Setelah lahan digambar lalu diberi pupuk organik terdahulu ke lahan dan didiamkan selama 3 hari agar pupuk meresap kedalam tanah. Setelah pupuk disebar secara merata ke gulutan lalu mengelus atau meratakan permukaan dengan menggunakan sebilah bambu.

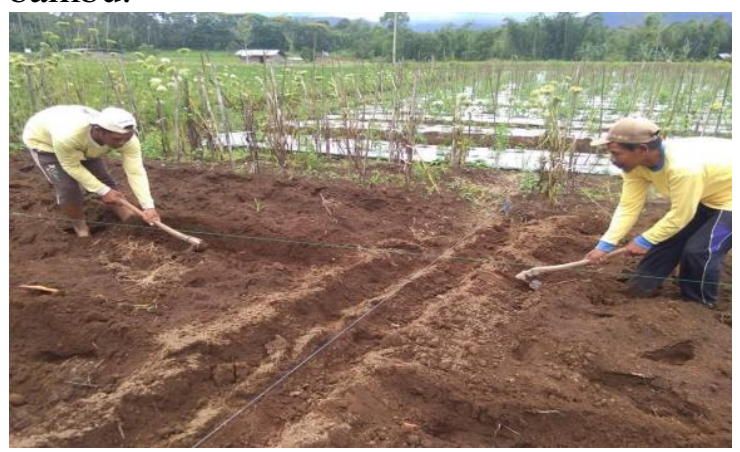

Gambar 6. Proses menggambar wortel sebelum diberi pupuk Sumber: Data primer

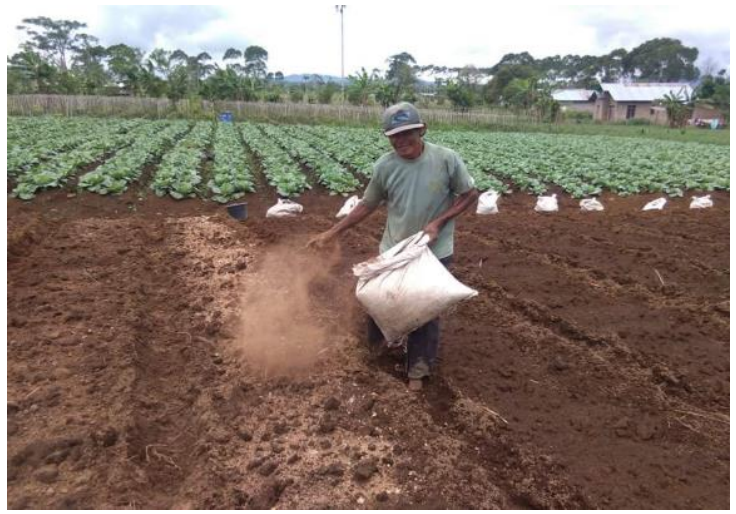

Gambar 7. Proses pemberian pupuk

Sumber: Data primer

\section{Penanaman atau Penaburan Bibit Wortel}

Bibit wortel di tabur kegulutan dengan rata supaya tumbuhan wortel tidak terlalu jarang. Wortel akan tumbuh secara merata pada umur 10 hari setelah tanam.

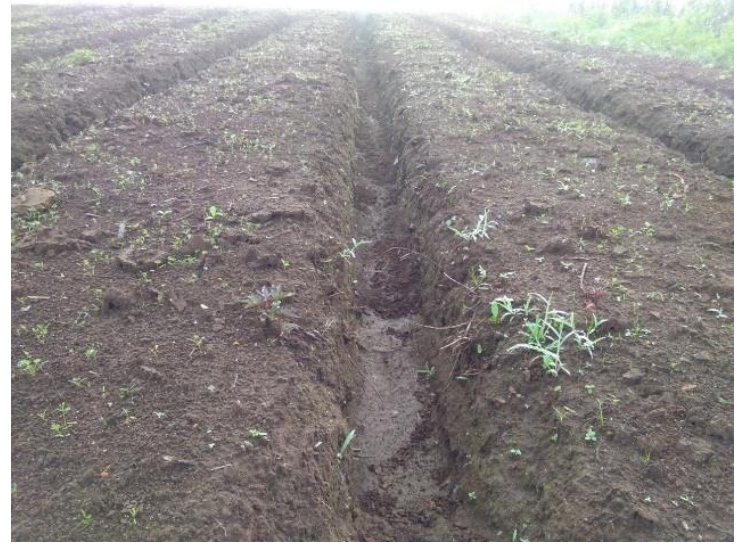

Gambar 8. Gulutan wortel

berumur 15 hari setelah tanam

Sumber : Data primer

\section{Penyiangan}

Penyiangan sangat perlu dilakukan supaya pertumbuhan wortel tumbuh dengan normal.

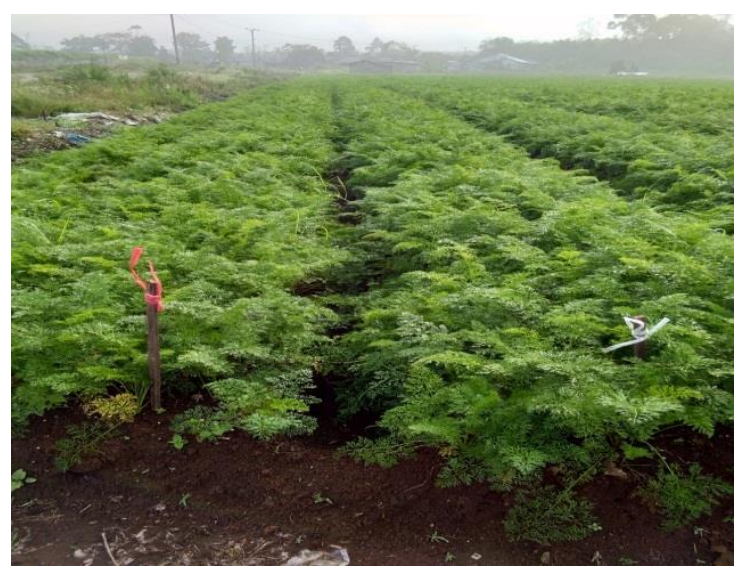

Gambar 9.Penyiangan dan penyemprotan tanaman umur 2,5 bulan.

Sumber : Data primer.

\section{Penyemprotan}

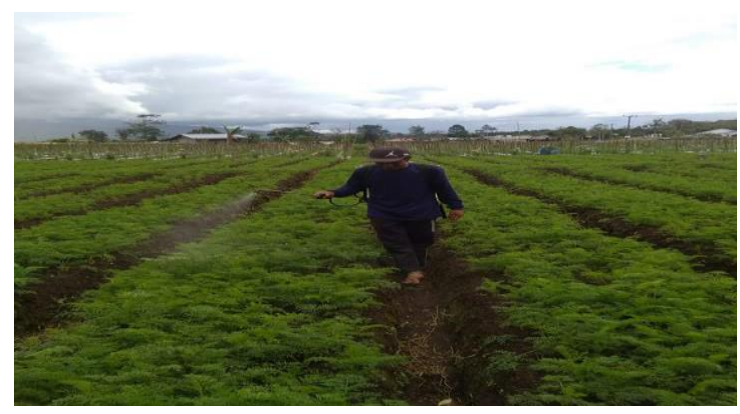

Gambar 10. Proses penyemprotan pupuk urin kelinci dan npk mutiara. 


\section{Pemanenan}

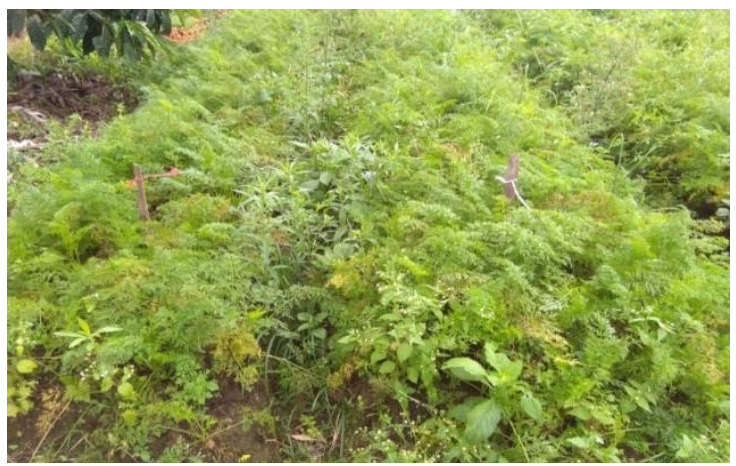

Gambar 11. Daun wortel berumur 3 bulan yang sudah bisa dipanen

Sumber : Data primer

Keterangan: Pada kayu tali merah menggunakan pupuk Npk (mutiara), tali putih menggunakan urin kelinci.

Tabel 3. Perbandingan Perkembangan Tinggi Tanaman Wortel Menggunakan Pupuk Urin Kelinci dan Pupuk Npk (Mutiara)

\begin{tabular}{|c|c|c|}
\hline \multicolumn{3}{|c|}{ Perkembangan tinggi tanaman } \\
\hline Minggu & $\begin{array}{c}\text { Urin kelinci } \\
(\mathrm{cm})\end{array}$ & $\begin{array}{c}\text { Npk (mutiara) } \\
(\mathrm{cm})\end{array}$ \\
\hline 1 & 1 & 1 \\
\hline 2 & 3 & 3 \\
\hline 3 & 4,8 & 4,9 \\
\hline 4 & 7 & 7,3 \\
\hline 5 & 8,9 & 9,3 \\
\hline 6 & 11,4 & 11,6 \\
\hline 7 & 13,4 & 13,9 \\
\hline 8 & 15,6 & 16,1 \\
\hline 9 & 17,5 & 18,2 \\
\hline 10 & 19,9 & 20,5 \\
\hline 11 & 22 & 22,6 \\
\hline 12 & 24,8 & 25,3 \\
\hline
\end{tabular}

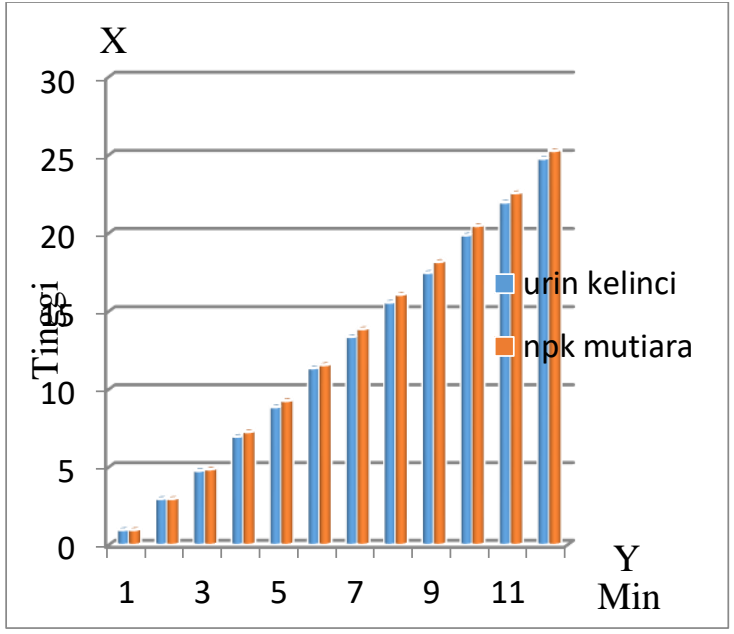

Gambar 12.. Diagram Laju Tinggi Pertumbuhan Tanaman Wortel.

Sumber : Data primer yang diolah

Tabel 4. Jumlah Ruas Daun Tanaman Wortel Yang Menggunakan Pupuk Urin Kelinci Dan Pupuk Npk (Mutiara)

\begin{tabular}{|c|c|c|}
\hline \multicolumn{3}{|c|}{ Jumlah ruas daun wortel } \\
\hline Minggu & Urin kelinci & Npk (mutiara) \\
\hline 1 & - & - \\
\hline 2 & 2 & 2 \\
\hline 3 & 3 & 3 \\
\hline 4 & 4 & 4 \\
\hline 5 & 5 & 5 \\
\hline 6 & 7 & 7 \\
\hline 7 & 8 & 8 \\
\hline 8 & 9 & 9 \\
\hline 9 & 10 & 10 \\
\hline 10 & 11 & 11 \\
\hline 11 & 12 & 12 \\
\hline 12 & 12 & 13 \\
\hline
\end{tabular}




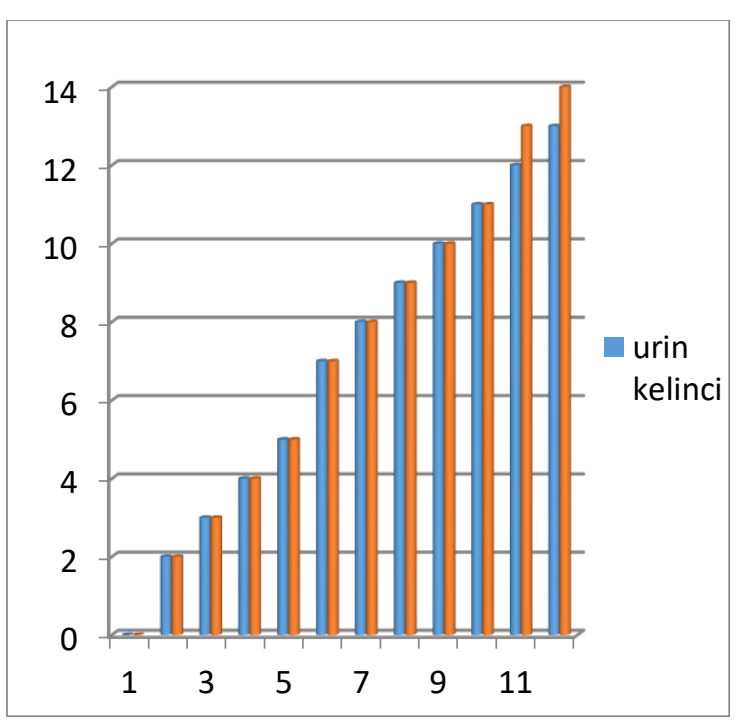

Gambar 4.8. Diagram 2. Jumlah ruas daun tanaman wortel.

Sumber : Data primer yang diolah

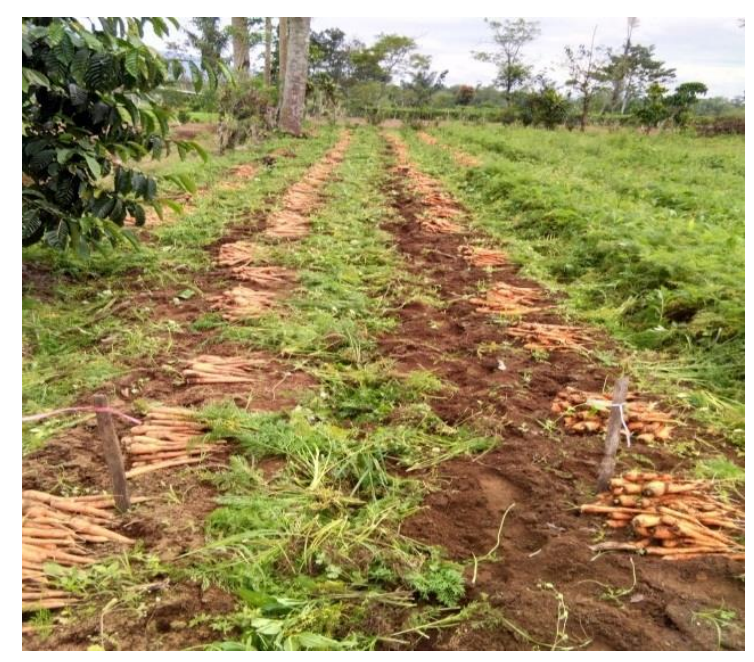

Gambar 4.9. Wortel yang dipanen berumur 3 bulan.

Sumber : Data primer.

Keterangan: 1. Tali merah menggunakan pupuk non-organik (npk mutiara) dengan pangkal umbi berdiameter $3,6 \mathrm{~cm}$.

2. Tali putih menggunakan pupuk organik (urin kelinci) dengan pangkal umbi berdiameter $3,5 \mathrm{~cm}$.
Tabel 5. Biaya Yang Dikeluarkan Untuk Penanaman Wortel Menggunakan Urin Kelinci Dengan Luas Lahan Yang Digunakan( 1x20 meter)

\begin{tabular}{|c|c|c|c|c|}
\hline \multicolumn{5}{|c|}{ Penanam an Wottel Menganakan Pupuk Utin Kelinci } \\
\hline No & Alat dan Bahan & Slat dan bahan & $\begin{array}{l}\text { Harga } \\
\text { Satuan } \\
(\mathrm{Rp})\end{array}$ & $\begin{array}{c}\text { Total Biays } \\
(\mathrm{Rp})\end{array}$ \\
\hline 1 & Cangkul * & 1 bugh & - & - \\
\hline 2 & Korete $*$ & 1 bush & - & - \\
\hline 3 & Tank sempotot * & 1 bugh & - & - \\
\hline 4 & Ember & 1 bugh & 10.000 & 10.000 \\
\hline 5 & Berrith wottel & 0,5 kaleng gus & 15.000 & 15.000 \\
\hline 6 & $\begin{array}{c}\text { Pupuk organik urin } \\
\text { kelinci }\end{array}$ & 5 liter & 2.000 & 10.000 \\
\hline 7 & Obat Regen & 1 botol $200 \mathrm{ml}$ & 35.000 & 35.000 \\
\hline \multicolumn{4}{|c|}{ Total } & 70.000 \\
\hline
\end{tabular}

Keterangan :

* Sebagian alat tidak masuk dalam perhitungan dalam penelitian penanaman wortel yang menggunakan pupuk organik urin kelinci dikarena peralatan sudah tersedia.

$$
\text { Perbedaan yang signifikan }
$$

Tabel 6. Biaya Yang Dikeluarkan Untuk Penanaman Wortel Menggunakan Pupuk Non-Organik Npk (Mutiara) Dengan Luas Yang Digunakan( 1x20 meter)

\begin{tabular}{|c|c|c|c|c|}
\hline No & Alat dan Bahan & $\begin{array}{c}\text { Jumlah Alat dan } \\
\text { bahan }\end{array}$ & $\begin{array}{c}\text { Harga } \\
\text { Satuan } \\
\text { (Rp) }\end{array}$ & $\begin{array}{c}\text { Total Biays } \\
(\mathrm{Rp})\end{array}$ \\
\hline 1 & Cangkul * & 1 buah & - & - \\
\hline 2 & Koret * & 1 buah & - & - \\
\hline 3 & Tank semprot* & 1 buah & - & - \\
\hline 4 & Ember & 2 buah & 10.000 & 20.000 \\
\hline 5 & Benih wortel & 0,5 kaleng susu & 15.000 & 15.000 \\
\hline 6 & $\begin{array}{l}\text { Pupuk Npk } \\
\text { (mutiara) }\end{array}$ & $2 \mathrm{~kg}$ & 17.000 & 34.0000 \\
\hline 7 & Obatregen & 1 botol $200 \mathrm{~m} 1$ & 35.000 & 35.000 \\
\hline \multicolumn{4}{|c|}{ Total } & 104.000 \\
\hline
\end{tabular}


Keterangan :

*Sebagian alat tidak masuk dalam perhitungan dalam penelitian penanaman wortel yang menggunakan pupuk NonOrganik Npk (Mutiara) dikarena peralatan sudah tersedia.

Perbedaan yang signifikan

Tabel 7. Hasil Wortel yang Dipanen

\begin{tabular}{|c|c|c|c|}
\hline No & Perhitungan & $\begin{array}{c}\text { Menggunakan } \\
\text { pupuk organik } \\
\text { Urin Kelinci }\end{array}$ & $\begin{array}{c}\text { Menggunakan } \\
\text { pupuk (Npk } \\
\text { mutiara) }\end{array}$ \\
\hline A & Luas Lahan $m^{2}$ & 0.05 & 0.05 \\
\hline B & Pedapatan wortel $(\mathrm{kg})$ & 100 & 105 \\
\hline C & Harga wortel $(\mathrm{Re})$ & 2.000 & 2.000 \\
\hline
\end{tabular}

Sumber: Data primer yang diolah.

Total penerimaan (Total Return) adalah perkalian antara produksi yang diperoleh dengan harga jual, secara matematis dirumuskan sebagai berikut.

Keterangan :

$$
\mathrm{TR}=\mathrm{P} \times \mathrm{Q}
$$

TR = Total Return / Total Penerimaan (Rp)

$$
\mathrm{P} \quad=\text { Price } / \text { Harga }(\mathrm{Rp} / \mathrm{Kg})
$$$$
\mathrm{Q}=\quad=\text { Quantity / Produksi }(\mathrm{Kg})
$$

a. Penerimaan penjualan menggunakan pupuk organik urin kelinci.

$\mathrm{TR}=\mathrm{P} \times \mathrm{Q}$

$\mathrm{TR}=\mathrm{Rp} 2000 \times 100$

$$
=\operatorname{Rp} 200.000
$$

b. Penerimaan pejualan menggunakan pupuk non-organik npk (mutiara).

$\mathrm{TR}=\mathrm{P} \times \mathrm{Q}$

$$
\begin{aligned}
\mathrm{TR} & =\operatorname{Rp} 2000 \times 105 \\
& =\operatorname{Rp} 210.000
\end{aligned}
$$

Menghitung pendapatan bersih sebagai berikut :

$$
\mathrm{I}=\mathrm{TR}-\mathrm{TC}
$$

Keterangan:

$$
\begin{array}{ll}
\mathrm{I} & =\text { Pendapatan }(\text { Income }) \\
\mathrm{TR} & =\text { Total return atau total penerimaan } \\
(\mathrm{Rp}) &
\end{array}
$$

$\mathrm{TC}=$ Total cost atau total biaya ( $\mathrm{Rp})$

a. Pendapatan bersih pejualan wortel menggunakan pupuk organik urin

\begin{tabular}{|c|c|c|c|}
\hline No & Pengamatan & Pupuk organik (urin kelinci) & $\begin{array}{c}\text { Pupuk non-organik (nok } \\
\text { mutiara) }\end{array}$ \\
\hline 1 & $\begin{array}{l}\text { Tinggi } \\
\text { wortel di } \\
\text { minggu } 12 \\
(\mathrm{~cm})\end{array}$ & 24,8 & 25,3 \\
\hline 2 & $\begin{array}{c}\text { Biava } \\
\text { produksi } \\
\text { (RP) }\end{array}$ & 70.000 & 104.000 \\
\hline 3 & $\begin{array}{c}\text { Penerimaan } \\
(\mathrm{Rp})\end{array}$ & 200.000 & 210.000 \\
\hline 4 & $\begin{array}{c}\text { Pendapatan } \\
(\mathrm{Rp})\end{array}$ & 130.000 & 106.000 \\
\hline 5 & $\begin{array}{l}\text { Tanah } \\
\text { setelah } \\
\text { tanam }\end{array}$ & $\begin{array}{l}\text { Tanah yang menggunakan } \\
\text { pupuk organik dapat } \\
\text { langsung diolah dan di } \\
\text { tanami tanpa harus di beri } \\
\text { pupuk kembali karena unsur } \\
\text { hara masih tersedia untuk } \\
\text { pertumbuhan tanaman. }\end{array}$ & $\begin{array}{l}\text { Tanah yang menggunakan } \\
\text { pupuk non-organik tidak } \\
\text { dapat langsung di tanami } \\
\text { tetapi hanus di pupuk } \\
\text { kembali di karenakan unsur } \\
\text { hara yang diberikan telah } \\
\text { berkurang. }\end{array}$ \\
\hline
\end{tabular}

kelinci. I = TR-TC

$=$ Rp. $200.000-$ Rp. 70.000

$=$ Rp. 130.000

b. Pendapatan bersih penjualan wortel menggunakan pupuk npk (mutiara)

$$
\begin{aligned}
\mathrm{I} & =\mathrm{TR}-\mathrm{TC} \\
& =\text { Rp. } 210.000-\text { Rp. } 104.000 \\
& =\text { Rp. } 106.000
\end{aligned}
$$

\section{Tabel 8. Hasil Penelitian dan Pengamatan}

Sumber: Data primer yang diolah

Perbedaan yang signifikan 


\section{Kesimpulan}

Berdasarkan hasil penelitian, diperoleh kesimpulan sebagai berikut :

a. Pertumbuhan tanaman wortel menggunakan pupuk organik urin kelinci dan pupuk non-organik npk (mutiara) tidak terlalu signifikan perbedaanya.

b. Terdapat perbedaan yang signifikan terhadap penerimaan hasil penjualan wortel yang menggunakan pupuk urin kelinci sebesar Rp. 200.000 dan pendapatan bersihnya adalah Rp.

\section{Daftar Pustaka}

Enny Mutryarny, Endriani, dkk. 2014. Pemanfaatan Urine Kelinci Untuk Meningkatkan Pertumbuhan dan Produksi Tanaman Sawi (Brassica Juncea L) Varietas Tosakan. Liquid Organic Rabbit Fertilizer Application On Growth And Production Of Mustard Varietas Tosakan.

Heru Prihmantono, Y.H. Indriani. 2017. Petunjuk Praktis Memupuk Tanaman Sayuran, Penerbit Penebar Surabaya.

H.R. Kartadisastra. 1997. Ternak Kelinci. Penerbit Kanisius (Anggota IKAPI). Yogyakarta.

Helvi Gustia. 2016. Respon Tanaman Wortel Terhadap Pemberian

https:// taniternakorganik.blogspot.com

Ir. Rahmat Rukmana. 1996. Bertanam Wortel. Penerbit Kanisius (Anggota IKAPI). Yogyakarta.

Nugroho, Panji. Panduan Membuat Pupuk Kompos Cair. Pustaka Baru Prees 2017.

Khairunisa. 2015. Pengaruh Pemberian Pupuk Organik, Anorganik Dan
130.000, sedangkan untuk pupuk nonorganik (npk mutiara) dimana penerimaan penjualan wortel kotor sebesar Rp. 210.000 dan pendapatan bersih Rp. 106.000.

c. Penggunaan pupuk organik urin kelinci lebih menguntungkan dalam hal biaya produksi yang lebih rendah $(\mathrm{Rp} 70.000)$ dan pendapatan yang lebih tinggi ( $\mathrm{Rp}$ 130.000) dibandingkan dengan pupuk non-organik (npk mutiara).

Kombinasinya Terhadap Pertumbuhan Dan Hasil Wortel.

Prasaja, Hadiedi. 2011. Air Kencing Kelinci Cairan Ajaib Untuk Pertanian. Artikel Serikat Petani Indonesia. Bogor.

Samadi, Budi. 2014. Rahasia Budidaya Wortel Sistem Organik. Pustaka Mina. Depok 
